\title{
Carbon-supported Nickel Catalyst Prepared from Steam-exploded Poplar by Recovering Ni(II)
}

\author{
Guangying Yang, Cheng Pan, * Haitao Yang, and Nianjie Feng \\ Poplar pretreated by steam explosion was used as an adsorbent to \\ simulate the adsorption process of nickel ion in wastewater. The result of \\ kinetics suggested that the pseudo-second-order model was well suited to \\ describing the adsorption of nickel ion. Through controlled adsorption, \\ steam-exploded poplar was recycled after $\mathrm{Ni}^{2+}$ adsorption and then \\ reduced to carbon-supported nickel catalyst ( $\mathrm{NiC700)}$. Spectrum analyses \\ of Fourier transform infrared spectrometry (FTIR), X-ray diffractometry \\ (XRD), X-ray photoelectron spectrometry (XPS), Brunauer Emmett-Teller \\ (BET) surface area, and electrochemical tests were applied to study the \\ properties of the NiC700 relative to the control carbonized materials \\ having no $\mathrm{Ni}(\mathrm{C} 700)$. The FTIR analysis revealed that there were chemical \\ interactions and ion changes between $\mathrm{OH}, \mathrm{C}-\mathrm{H}, \mathrm{C}=\mathrm{O}$, and heavy metal \\ ions in the bio-adsorption process of nickel. The surface area of NiC700 \\ was $1480 \mathrm{~m}^{2} / \mathrm{g}$. The presence of Ni nanoparticles in NiC700 after reduction \\ was confirmed by the XRD and XPS analyses. Electrochemical \\ impedance spectroscopy (EIS), photocurrent (IT), and Mott Schottky curve \\ results revealed that the conduction band potential of NiC700 ( $\left.E_{\mathrm{CB}, \mathrm{NiC} 700}\right)$ \\ was $-0.10 \mathrm{eV}$ vs. RHE (reversible hydrogen electrode) as an n-type \\ semiconductor, and the Ni-doped carbon fiber exhibited certain \\ electrophotocatalytic activity due to the nickel modification.
}

Keywords: Steam explosion; Nickel catalyst; Poplar

Contact information: Hubei Provincial Key Laboratory of Green Materials for Light Industry, Hubei University of Technology, Wuhan 430068, China; *Corresponding author: pcqian837@ sina.com

\section{INTRODUCTION}

Because nickel is a hard, heavy metal with good corrosion resistance, nickel or its alloys are widely used in the electroplating industry. High amounts of nickel electroplating wastewater and nickel-containing wastewater are produced every year (Sulaiman and Othman 2017; Su et al. 2020). Relatively modest concentrations of Ni in water (>10 $\mu \mathrm{g} / \mathrm{L})$ have toxic effects on human health. Because it is environmentally friendly, has a low cost, consists of a simple process, and has a good treatment effect, the adsorption method stands out from traditional treatments.

Agricultural and forestry waste is a large green biomass resource that produces approximately 700 million tons of crop straw every year in China, $70 \%$ of which is rice straw, wheat straw, and corn straw. The need for a method to create new high value-added products has become particularly urgent. Bio-based products are green and environmentfriendly. In spite of the amount of energy consumed in the preparation of bio-based materials, bio-based materials are more in line with the requirements of sustainable development and environmental protection than petroleum-based materials. Many bioadsorbents have been employed to control heavy metal ions. Many studies have found that the structure of biomass and the pretreatment process have a great impact on the physical and chemical properties of carbon materials (Woolf et al. 2010; Qian et al. 2015). 
Steam explosion is an alternative pretreatment technology in the field of biomass conversion. Conducted under high temperature and high pressure, the hydrogen bond inside the cellulose is broken and new hydroxyl groups are released, which results in the increase of the specific surface area of cellulose and the adsorption capacity of the explosive products (Ballesteros et al. 2002; Panda et al. 2007; Darmawan et al. 2016). In this way, the solvent molecules can easily enter into the fiber structure, and the infiltrated solvent can fully contact with cellulose, which promotes the adsorption capability of catalyst and the conversion of carbon materials.

Nickel-supported catalysts can be used as key materials in many fields (Liu et al. 2018; Li et al. 2019). As the demand for clean and renewable fuels continues to increase, the importance of bio-oil hydrofining has become more prominent. A nickel-supported catalyst composed of rice husk activated carbon and nickel can be used to catalyze the hydrodeoxidation of vanillin to 4-methylguaiacol. Ni, Fe, and other metals can be used as catalysts for the graphitization of carbon materials, which can reduce the graphitization temperature of carbon materials ( $\mathrm{Li}$ et al. 2011; Liu et al. 2015). The concept of intermetallic compound provides a research direction for carbon materials doped with polymetallic particles (Gong et al. 2020). In recent years, heteromaterials bonded by transition metals and carbon have shown high ability to OER (Song et al. 2020). Nickel catalyst supported on activated carbon has better desulfurization performance at low temperature than those of original activated carbon samples and metal carrier system (Selvavathi et al. 2008). Similarly, the preparation of Ni-based metal catalysts supported on non-noble metals is a feasible route for ethanol fuel cells (Shi et al. 2016).

Exploring the appropriate size of adsorption materials that are easily separated, can effectively adsorb heavy metal ions, and can proceed to the next step to realize the high value application of heavy metals and adsorption materials is the goal of several researchers or enterprises. In this study, steam-exploded poplar wood was used as an adsorbent for the removal of nickel ions in aqueous solution. The mechanism of adsorbing the catalyst $(\mathrm{Ni})$ for steam-exploded materials was considered via the adsorption kinetic model (Azizian 2004; Berber-Mendoza et al. 2018; Khulbe and Matsuura 2018). Structural features of NiC700 and C700 were characterized and extensively compared by spectroscopic analyses, which included Fourier transform infrared spectrometry (FTIR), X-ray diffractometry (XRD), X-ray photoelectron spectrometry (XPS), Brunauer Emmett-Teller (BET) surface area analysis, and electrochemical tests. In addition, steam-exploded poplar wood can be used as a biofunctional material that is an excellent adsorbent and a good catalyst carrier.

\section{EXPERIMENTAL}

\section{Materials}

Poplar was steam exploded at $213{ }^{\circ} \mathrm{C}$ for $5 \mathrm{~min}$. The compositional analysis of steam-exploded poplar (SEP) on a dry basis was carried out as described to determine the glucan (71.7\%), xylan (4.0\%), and lignin (13.0\%) contents. All standards and chemical compounds, which included xylose, glucose, arabinose, and cellulose, were chromatography grade and procured from Sigma-Aldrich (Shanghai, China). Nickel chloride hexahydrate was analytical grade and procured from Sinopharm Chemical Reagent Co., Ltd. (Shanghai, China). 


\section{Adsorption Kinetics Experiment}

To investigate the adsorption kinetics, $0.1 \mathrm{~g}$ of steam-exploded poplar was screened to the range 40-mesh to 60-mesh and immersed in $50 \mathrm{~mL}$ of an aqueous solution of nickel with a concentration of $4.5257 \mathrm{~g} / \mathrm{L}$. The flasks were sealed and continuously stirred in an air bath at $50{ }^{\circ} \mathrm{C}$. Solutions of $2 \mathrm{~mL}$ in volume were removed at 20 min intervals and diluted into $50 \mathrm{~mL}$ with water. The concentrations of nickel in the solutions were then measured by flame atomic absorption spectrophotometry (AA-6300C, Shimadzu Corporation, Kyoto, Japan). The amount of $\mathrm{Ni}$ adsorption at time $t\left(q_{\mathrm{t}}\right)$ was calculated using the following equation (Eq. 1),

$$
q_{t}=\frac{\left(C_{0}-C_{t}\right) V}{m}
$$

where $q_{\mathrm{t}}$ is the uptake of $\mathrm{Ni}^{2+}(\mathrm{g} / \mathrm{g}), C_{0}$ and $C_{\mathrm{t}}(\mathrm{g} / \mathrm{L})$ are the concentrations of $\mathrm{Ni}^{2+}$ in the solution initially and at time $t$, respectively, $V$ is the volume of the solution (L), and $m$ is the total mass of the sorbent (g) used in Ni sorption (He et al. 2013).

\section{Nickel-supported Catalyst Preparation}

Steam-exploded poplar prepared at $213{ }^{\circ} \mathrm{C}$ for 5 min by steam explosion adsorbed with nickel ions (SEP-Ni) was pyrolyzed. The following conditions were employed. The temperature was increased at a rate of $5{ }^{\circ} \mathrm{C} / \mathrm{min}$ under nitrogen protection, and the feedstock was held for $3 \mathrm{~h}$ at $700{ }^{\circ} \mathrm{C}$. Then it was cooled to room temperature inside the furnace. The carbon material was referred to as NiC700. As a control, the carbon material was prepared from steam-exploded poplar under the same conditions and referred to as C700 (Fig. 1).

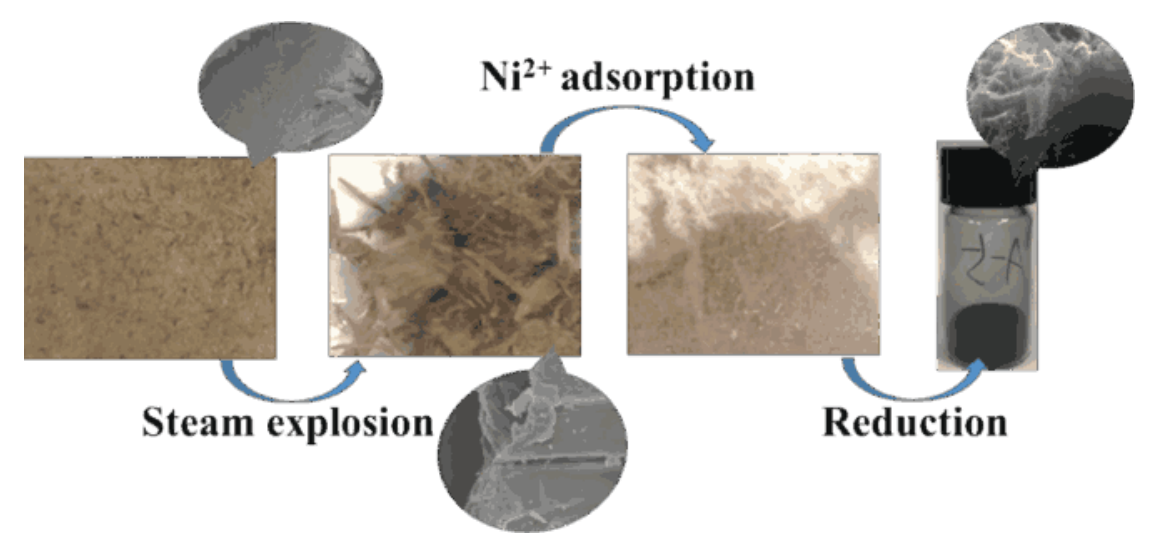

Fig. 1. Schematic illustration of the formation of $\mathrm{NiC700}$ and the $\mathrm{C} 700$ composite

\section{Biochar Characterization}

The crystal structures of the samples were analyzed by XRD using an X-ray diffractometer (Ultima IV, Rigaku Corporation, Tokyo, Japan) with $\mathrm{Cu}$ Ka radiation operated at $40 \mathrm{kV}$ and $30 \mathrm{~mA}$. The chemical composition was analyzed via XPS using an ESCALAB 250 analyzer (Thermo Scientific, Waltham, MA, USA) with a monochromated Al Ka X-ray source. The FTIR analysis was performed using a Fourier transform infrared spectrometer (Vertex 70, Bruker, Karlsruhe, Germany) using the KBr pellet technique. The $\mathrm{N}_{2}$ adsorption-desorption isotherm measurements were performed with a BELSORP-mini 
II instrument (APSP2020, Micromeritics, Norcross, GA, USA) using the BET method (Alam et al. 2018).

\section{Electrochemical Characterization}

All electrochemical measurements were conducted on a computer-controlled CHI 660E electrochemical workstation (Chenhua Instrument, Shanghai, China) with a conventional three electrode system, which included a Pt wire counter electrode, an $\mathrm{Hg} /$ $\mathrm{HgO}$ reference electrode, and an indium tin oxide (ITO) working electrode. The $10 \mathrm{mg}$ powder sample was dispersed in $1 \mathrm{~mL}$ ultra-pure water / ethanol solution, and then $50 \mu \mathrm{L}$ of Nafion ethanol solution was added. The system was exposed to ultrasonic vibrations for 30 minutes to form a uniform suspension, then $30 \mu \mathrm{L}$ suspension were dripped on ITO glass and dried at room temperature. The base solution for the photoelectric test was $0.5 \mathrm{M}$ sodium sulfate solution, the bias voltage was $0 \mathrm{~V}$, the illumination interval was $30 \mathrm{~s}$ (the light was turned on for $30 \mathrm{~s}$ and then turned $30 \mathrm{~s}$ ) with over four cycles, and the light source was a xenon lamp (>420 nm). The frequency range of the electrochemical impedance spectroscopy (EIS) test was $0.1 \mathrm{~Hz}$ to $100 \mathrm{kHz}$, and the electrolyte was a potassium ferricyanide solution $(2.5 \mathrm{mmol} / \mathrm{L}$ of potassium ferricyanide and $0.1 \mathrm{~mol} / \mathrm{L}$ of $\mathrm{KCl})$. The test frequency of the Mott-Schottky curve was $1000 \mathrm{~Hz}$, the potential range was $-1 \mathrm{~V}$ to 1 $\mathrm{V}$, and the base solution was a $0.5 \mathrm{M}$ sodium sulfate solution.

\section{RESULTS AND DISCUSSION}

\section{Adsorption Kinetics}

Adsorption kinetics play a key role in determining the adsorption rate and efficiency of heavy metals in aqueous solution (Ruan et al. 2016; Yin et al. 2018). The curves of $\mathrm{Ni}^{2+}$ concentration are shown in Fig. 2. The kinetics of $\mathrm{Ni}^{2+}$ adsorption on steamexploded poplar obtained by batch adsorption time were studied with an initial concentration of $4.5257 \mathrm{~g} / \mathrm{L}$ at $50{ }^{\circ} \mathrm{C}$.

To understand the detailed characteristics of the adsorption, three known kinetic models, which were the pseudo-first-order equation, the pseudo-second-order equation (Ho and McKay 1999), and the Elovich equation were used to fit the kinetic experimental data. The three non-linear form expressions were calculated as follows,

$$
\begin{aligned}
& \log \left(q_{e}-q_{t}\right)=\log q_{e}-\frac{k_{1}}{2.303} t \\
& \frac{t}{q_{t}}=\frac{1}{k_{2} q_{e}^{2}}+\frac{1}{q_{e}} t \\
& q_{t}=\frac{1}{\beta} \ln (\alpha \beta)+\frac{\ln t}{\beta}
\end{aligned}
$$

where $q_{\mathrm{e}}$ and $q_{\mathrm{t}}$ are the amount of dye adsorbed $(\mathrm{mg} / \mathrm{g})$ at equilibrium and at $t$ time (min), respectively, $k_{1}$ is the pseudo-first-order equilibrium rate constant $(\mathrm{L} / \mathrm{min}), k_{2}$ is the pseudosecond-order equilibrium rate constant $(\mathrm{g} / \mathrm{mg} \times \mathrm{min}), \alpha(\mathrm{g} / \mathrm{g} \times \mathrm{min})$ is the initial adsorption rate constant, and $\beta(\mathrm{g} / \mathrm{g} \times \mathrm{min})$ is a constant related to the activation energy of adsorption from the Elovich equation. 
Table 1 shows the estimated kinetic parameters and coefficients of determination $\left(\mathrm{R}^{2}\right)$ of the three models (Origin, OriginLab, v.2019b, Northampton, MA, USA). The value of $\mathrm{R}^{2}(0.822)$ from the pseudo-first-order model was particularly low, which suggested that the adsorption process did not conform to the pseudo-first-order kinetic model. Through the linear fitting of Elovich equation, the initial adsorption rate constant $\alpha(0.059 \mathrm{~g} / \mathrm{g} \times \mathrm{min})$ and the constant $\beta$ related to adsorption activation energy $\beta(22.88 \mathrm{~g} / \mathrm{g} \times \mathrm{min})$, but the value of $R^{2}(0.755)$ in Elovich equation were obtained, which indicated that this equation could not well describe the process of nickel ion adsorption by steam-exploded poplar.

a
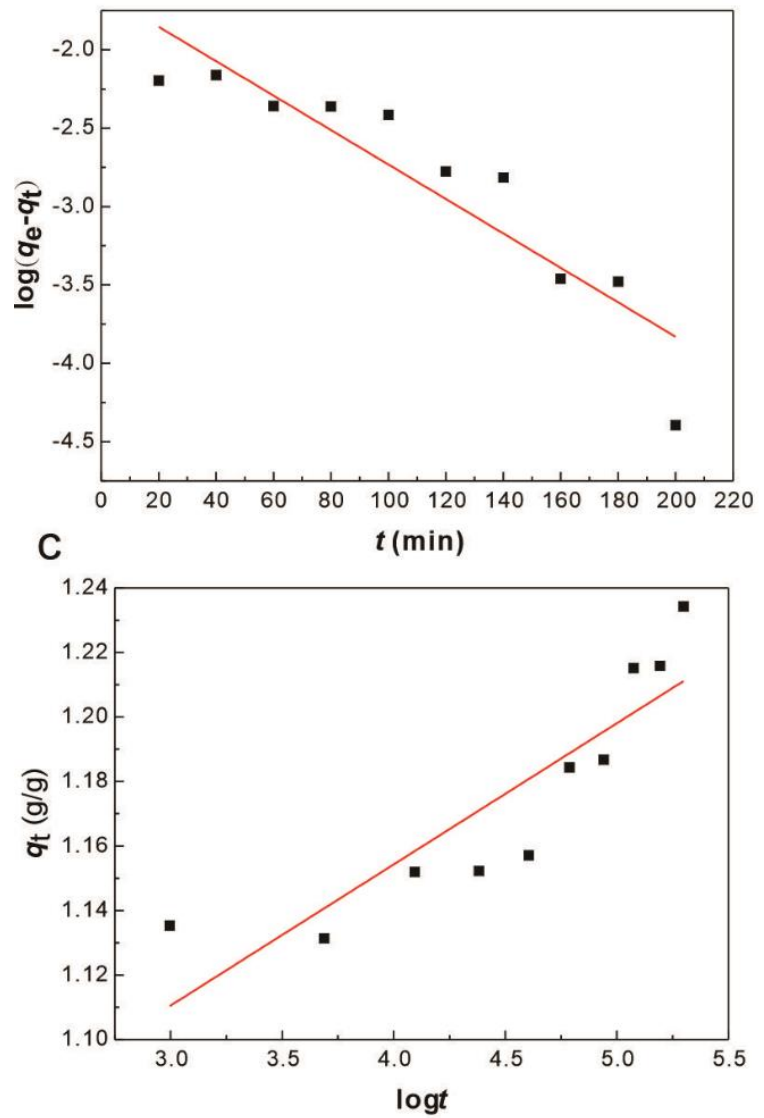

$\mathrm{b}$

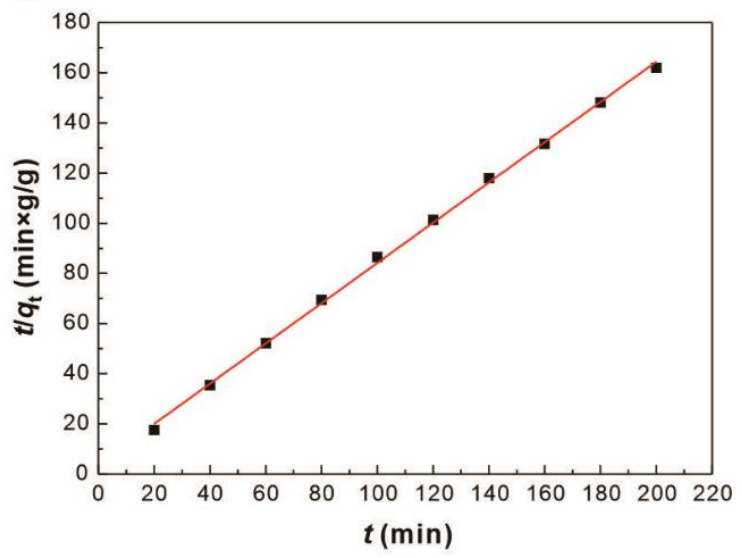

Fig. 2. The adsorption of $\mathrm{Ni}^{2+}$ onto steam-exploded poplar: (a) Pseudo-first-order kinetics; (b) pseudo-second-order kinetics; (c) Elovich equation

Table 1. Adsorption Kinetic Parameters of Pseudo-first-order Model, Pseudosecond-order Model, and Elovich Equation for $\mathrm{Ni}^{2+}$ Adsorption by Steamexploded Poplar

\begin{tabular}{|c|c|c|c|c|c|}
\hline Model & $\begin{array}{c}k_{1} \\
\left(\mathrm{~min}^{-1}\right)\end{array}$ & $\begin{array}{c}k_{2} \\
(\mathrm{~g} / \mathrm{g} \times \mathrm{min})\end{array}$ & $\begin{array}{c}\alpha \\
(\mathrm{g} / \mathrm{g} \times \mathrm{min})\end{array}$ & $\begin{array}{c}\beta \\
(\mathrm{g} / \mathrm{g} \times \mathrm{min})\end{array}$ & $\mathrm{R}^{2}$ \\
\hline Pseudo-first-order & 0.011 & & & & 0.822 \\
\hline Pseudo-second-order & & 0.163 & & & 0.999 \\
\hline Elovich Equation & & & 0.059 & 22.88 & 0.755 \\
\hline
\end{tabular}


The value of $\mathrm{R}^{2}$ (0.999) from the pseudo-second-order model suggested that the pseudo-second-order model was well suited to describe the adsorption of nickel ion by steam-exploded poplar (Hubbe et al. 2019, 2021). The results indicated that chemical and physical adsorption simultaneously are occurring and that diffusion into a network of pores is likely to be the rate-controlling factor.

\section{FTIR Analysis}

The FTIR analyzer was used to identify the functional groups on the SEP samples' surface, which are shown in Fig. 3. The FTIR spectra showed strong absorption at 3415 $\mathrm{cm}^{-1}$, which was attributed to stretching of the phenolic and aliphatic hydroxyl groups. The $\mathrm{C}-\mathrm{H}$ stretching and asymmetric vibrations of $\mathrm{CH}_{3}$ and $\mathrm{CH}_{2}$ absorption appeared at 2921 $\mathrm{cm}^{-1}$. The infrared absorption peaks at $1738 \mathrm{~cm}^{-1}, 1507 \mathrm{~cm}^{-1}$, and $1374 \mathrm{~cm}^{-1}$ were associated with the xylan in hemicellulose, the benzene ring in lignin, and the C-O-C in cellulose, respectively (Reddy et al. 2018). Two strong absorption peaks at $1060 \mathrm{~cm}^{-1}$ and $1035 \mathrm{~cm}^{-}$ ${ }^{1}$ belonged to the stretching vibration of $\mathrm{C}-\mathrm{O}$ in $\mathrm{C}_{3}$ and the stretching vibration of $\mathrm{C}-\mathrm{C}$ in $\mathrm{C}_{6}$, respectively.

After the adsorption of nickel ions, the position and intensity of the hydroxyl group (approximately $3415 \mathrm{~cm}^{-1}$ ) changed compared to the pre-adsorption state. Peaks at around $2921 \mathrm{~cm}^{-1}$ that were related to the $\mathrm{C}-\mathrm{H}$ functional group changed after the bio-adsorption of nickel using SEP. The results showed that there were chemical interactions and ion changes between $\mathrm{OH}, \mathrm{C}-\mathrm{H}, \mathrm{C}=\mathrm{O}$, and heavy metal ions in the bio-adsorption process of nickel (Foroutan et al. 2019).

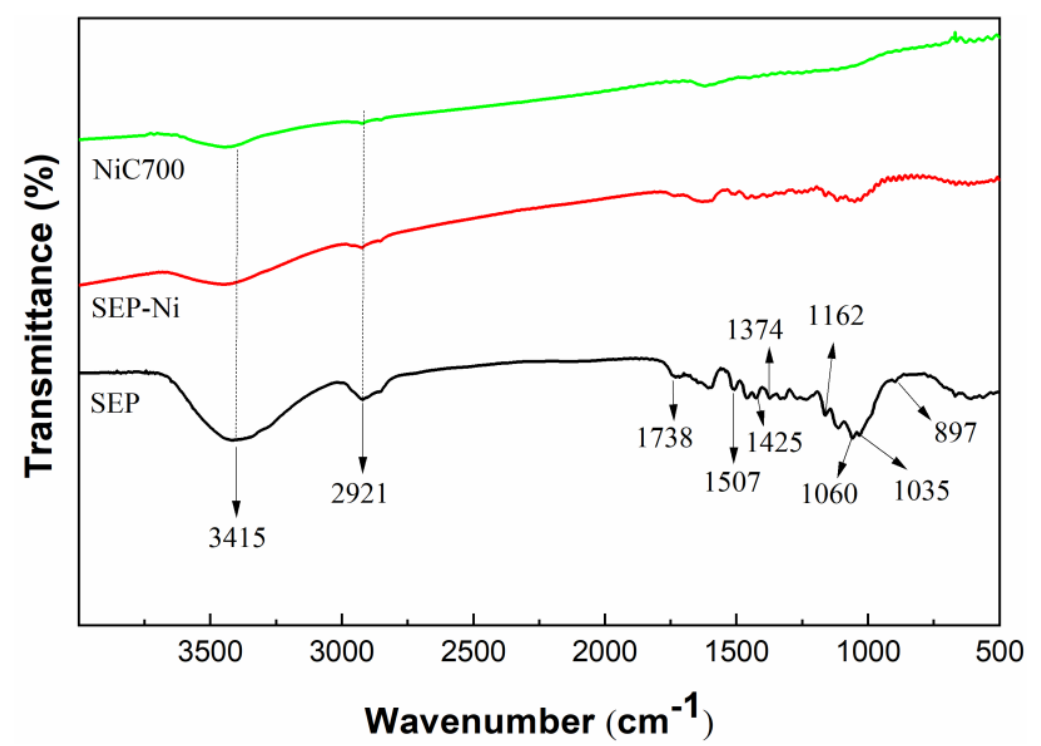

Fig. 3. The FTIR spectra of SEP, SEP-Ni, and NiC700

\section{BET Analysis}

Nitrogen adsorption was performed for the NiC700 and C700 samples to evaluate the permanent porosity (Fig. 4). The isotherm of NiC700 was a reversible type II isotherm, which is one of the main characteristics of mesoporous materials. The surface area of NiC700 was calculated as $1480 \mathrm{~m}^{2} / \mathrm{g}$ using the BET model. Compared to the specific surface area of C700 $\left(789 \mathrm{~m}^{2} / \mathrm{g}\right)$, the adsorption of nickel ion played an important role in the increase of the specific surface area of carbon material. 


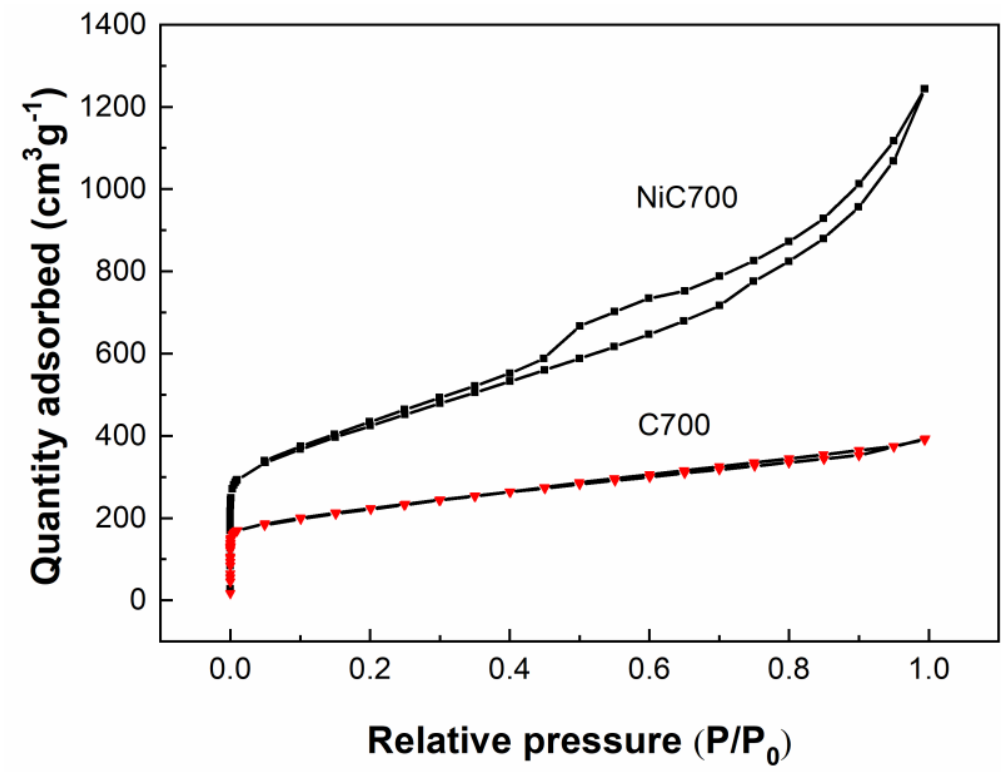

Fig. 4. $\mathrm{BET}$ of $\mathrm{NiC} 700$ and $\mathrm{C} 700$

\section{XPS and XRD Analysis}

The structure and chemical compositions of the NiC700 and C700 were examined using XRD and XPS, respectively. Figure 5 shows the XRD pattern of the NiC700 sample compared to $\mathrm{C} 700$. All of the peak reflections in the diffraction pattern of NiC700 matched well with Ni reference data. The XRD pattern of NiC700 and C700 contained a broad diffraction peak at about $23.07^{\circ}$ and a weak peak at $43.39^{\circ}$, which were ascribed to the (002) and (100) planes of carbon, respectively (Zhong et al. 2018).

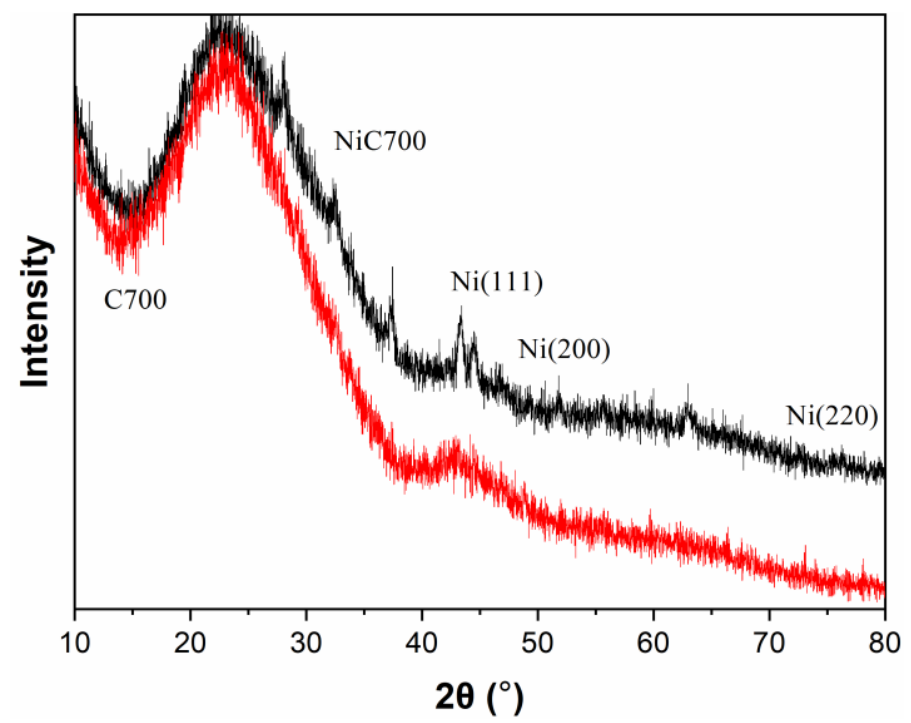

Fig. 5. The XRD pattern of $\mathrm{NiC700}$ and $\mathrm{C} 700$

The sharp peak at approximately $26.38^{\circ}$ indicated that there was high crystallinity of carbon (the high-level graphitization of carbon), which could possess better corrosion resistance to harsh alkaline electrolytes than amorphous carbon. In contrast, at 
approximately $44.48^{\circ}, 51.76^{\circ}$, and $76.36^{\circ}$, three diffraction peaks of nickel metal were determined in the NiC700 sample, and the corresponding crystal planes were (111), (200), and (220), respectively (Cao et al. 2014). The NiO diffraction peak was not observed. This indicated that, when the nickel-based activated carbon catalyst was calcined in an inert atmosphere at $700{ }^{\circ} \mathrm{C}$, the $\mathrm{NiO}$ was reduced to nickel by the reducing substance (Kim et al. 2018). These results indicated the successful formation of highly dispersed nickel particles on the surface of carbonized steam explosion fiber.

The chemical states of NiC700 and C700 were examined by XPS, which was used to characterize the $\mathrm{Ni}$ oxidation state. The XPS spectrum of NiC700 demonstrated the presence of $\mathrm{C}$, O, and $\mathrm{Ni}$ elements. In contrast, C700 contained only $\mathrm{C}$ and $\mathrm{O}$ (Fig. 6a). The split peaks of the $\mathrm{C}_{1 \mathrm{~s}}$ spectrum demonstrated that the surface of NiC700 contained different $\mathrm{C}$ bonds, which included $\mathrm{C}=\mathrm{C} / \mathrm{C}-\mathrm{C}, \mathrm{C}-\mathrm{O}, \mathrm{C}=\mathrm{O}$, and $\mathrm{O}-\mathrm{C}=\mathrm{O}$ bonds located at $284.33 \mathrm{eV}, 285.33 \mathrm{eV}, 286.33 \mathrm{eV}$, and $287.33 \mathrm{eV}$, respectively. These findings indicated the presence of carbon and hydrophilic oxygen functionalities (Zhou et al. 2015). This was also verified by the $\mathrm{O}_{1 \mathrm{~s}}$ spectra (Fig. $6 \mathrm{~b}$ ) that had typical peaks of $-\mathrm{C}=\mathrm{O}$ bonds $(533.2 \mathrm{eV})$, $-\mathrm{C}-\mathrm{O}$ bonds $(532.1 \mathrm{eV})$, and Ni-O-C bonds $(530.9 \mathrm{eV})$. The formation of Ni-O-C bonds could improve the affinity of Ni nanoparticles to carbon substrate. The high resolution XPS spectrum of Ni2p (Fig. 6d) contained two peaks centered at $855.3 \mathrm{eV}$ and $861.4 \mathrm{eV}$ that were assigned to $\mathrm{Ni} 2 \mathrm{p}_{3 / 2}$ and $\mathrm{Ni} 2 \mathrm{p}_{1 / 2}$, respectively (Zhong et al. 2018), which confirmed the presence of Ni nanoparticles in NiC700 after reduction (Li et al. 2019).
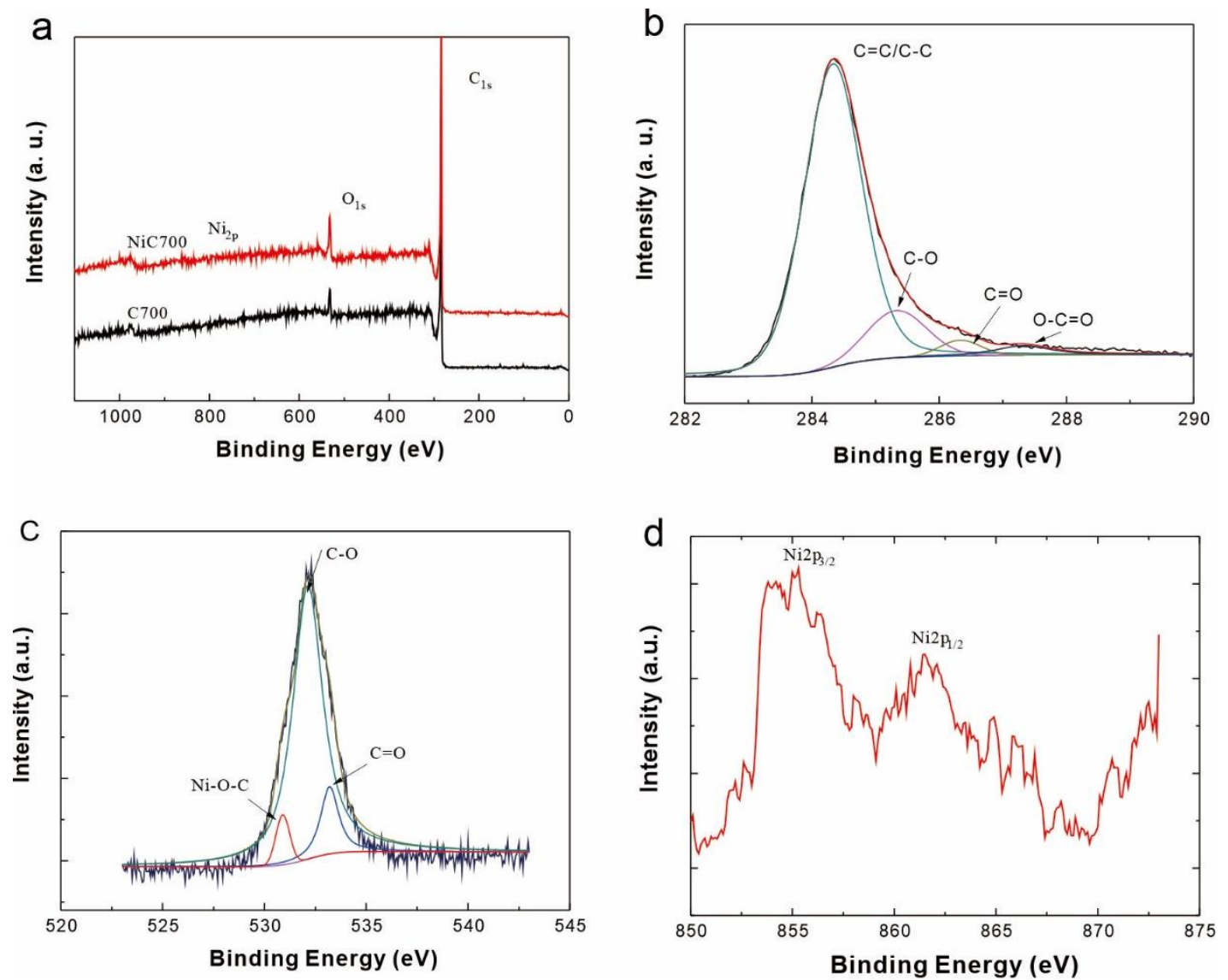

Fig. 6. The XPS spectra of NiC700 and C700: (a) survey XPS spectrum; High resolution XPS spectrum of (b) $\mathrm{C}_{1 \mathrm{~s}}$, (c) $\mathrm{O}_{1 \mathrm{~s}}$, and (d) $\mathrm{Ni}_{2 \mathrm{p}}$ 


\section{Electrochemical Performance Analysis}

The electrochemical performances of $\mathrm{NiC700}$ and $\mathrm{C} 700$ were characterized systematically ( $\mathrm{Li}$ et al. 2019). Mott-Schottky testing is a common method to test the electrochemical performance of semiconductor materials by using electrochemical workstation. The type and flat band potential of semiconductors can be determined by the Mott-Schottky test. The redox ability of the catalyst was related to the position of the valence band of the conduction band. To estimate the conduction band edge potentials, the flat band potentials of the samples were investigated via a Mott-Schottky plot (Fig. 7a). Notably, NiC700 is an n-type semiconductor because it has a positive slope in the MottSchottky plot (Wen et al. 2017). In general, the $E_{\mathrm{CB}}$ for n-type semiconductors is close to the flat band (Zong et al. 2008). As Fig. 7a shown, the $E_{\mathrm{FB}, \mathrm{NiC} 700}$ was $0.10 \mathrm{eV} v s$. RHE, which can be obtained by intercept on the abscissa. For n-type semiconductors, the flat band (FB) potential is $0.2 \mathrm{eV}$ higher than the conduction band (CB) potential (Zheng and Zhang 2018). From this, it can be calculated that the $E_{\mathrm{CB}}$, NiC700 was $-0.10 \mathrm{eV}$ vs. RHE.
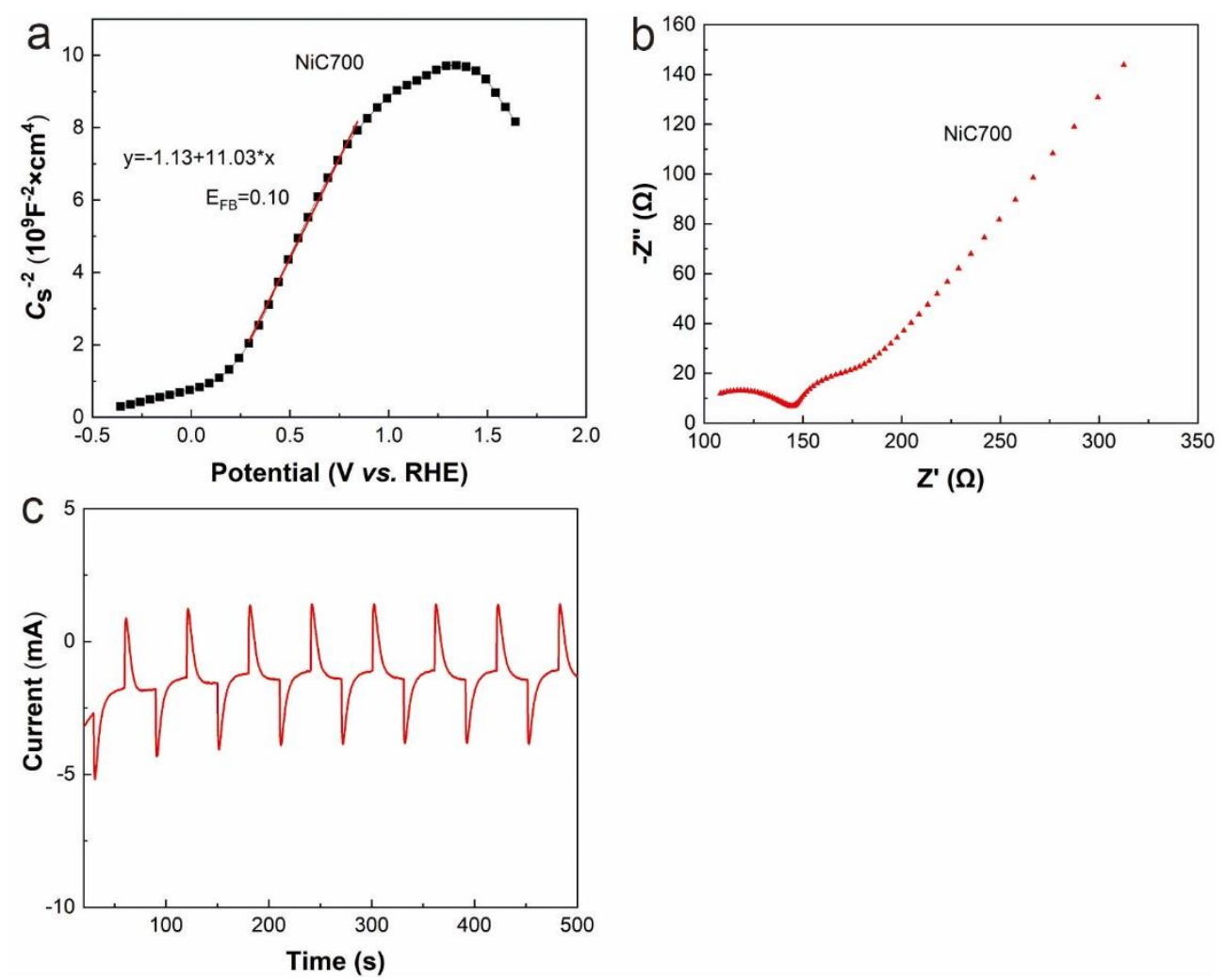

Fig. 7. The electrochemical performances of NiC700 and C700: (a) Mott Schottky plots (Frequency $=1000 \mathrm{~Hz}$, potential range $=-1 \mathrm{~V}$ to $1 \mathrm{~V}$, and the bottom solution $=0.5 \mathrm{M}$ sodium sulfate solution); (b) Electrochemical impedance spectroscopy (test frequency range $=0.1 \mathrm{~Hz}$ to $100 \mathrm{kHz}$, and the electrolyte = potassium ferricyanide solution); (c) IT photocurrent (base solution $=0.5 \mathrm{M}$ sodium sulfate solution, bias voltage $=0 \mathrm{~V}$, and illumination interval $=30 \mathrm{~s}$

The effects of cathode internal resistance effects were examined by conducting EIS measurements. Figure $7 \mathrm{~b}$ shows that the Nyquist plots of the cathode gave information on the charge transfer characteristics. In general, a smaller arc radius indicates higher charge transfer efficiency (Zou et al. 2017). A semicircle was observed for the NiC700 cathode, which indicated higher interfacial charge transfer and a more effective separation of carriers. In addition, the electrochemical performance of the electrodes is affected by the 
content of $\mathrm{Ni}$ in the carbon. In addition, the photocurrent response of the NiC700 sample in Fig. 7c reflected that there was efficient separation, and the photo-excited $\mathrm{e}^{-} / \mathrm{h}^{+}$pairs of NiC700 had long lifetimes (Reddy et al. 2017). The transient photocurrent responses of $\mathrm{NiC700}$ were examined to determine the clean energy generation properties of the prepared sample. Figure 7c shows that the electrode generated photocurrent that had a reproducible response to on/off cycles under visible light irradiation. Clearly, the Ni-doped carbon fiber exhibited a certain photocurrent density, which demonstrated the enhancement of visible light electrophotocatalytic activity via the nickel modification.

\section{CONCLUSIONS}

1. Steam-exploded poplar was studied as an adsorbent for the removal of nickel ions in aqueous solution, and further carbonization into nickel-rich catalyst was a feasible method of application. The kinetic model of the adsorption process confirmed pseudosecond order kinetics. The FTIR results showed that there were chemical interactions and ion changes between $\mathrm{OH}, \mathrm{C}-\mathrm{H}, \mathrm{C}=\mathrm{O}$, and heavy metal ions in the bio-adsorption process of nickel. The isotherm of $\mathrm{NiC} 700$ was a reversible type II isotherm, and the surface area was $1480 \mathrm{~m}^{2} / \mathrm{g}$, which was larger than that of C700 $\left(789 \mathrm{~m}^{2} / \mathrm{g}\right)$.

2. In addition, the adsorbed $\mathrm{Ni}$ ions were evenly distributed across the NiC700 surface, which was confirmed by XRD and XPS. The adsorption of $\mathrm{Ni}^{2+}$ was recycled to nickelrich catalyst, which had certain visible light electrophotocatalytic activity. The steamexploded poplar adsorbed nickel ions were converted to nickel catalyst, which substantially increased their value.

\section{ACKNOWLEDGMENTS}

The authors are grateful for the support of the National Nature Science Foundation of China (NNSFC; Grant No. 21978074).

\section{REFERENCES CITED}

Alam, M. S., Gorman-Lewis D., Chen, N., Flynn, S. L., Ok, Y. S., Konhauser, K. O., and Alessi, D. S. (2018). "Thermodynamic analysis of nickel(II) and zinc(II) adsorption to biochar," Environmental Science \& Technology 52(11), 6246-6255. DOI: 10.1021/acs.est.7b06261

Azizian, S. (2004). "Kinetic models of sorption: A theoretical analysis," Journal of Colloid and Interface Science 276(1), 47-52. DOI: 10.1016/j.jcis.2004.03.048

Ballesteros, I., Oliva, J. M., Negro, M. J., Manzanares, P., and Ballesteros, M. (2002). "Enzymic hydrolysis of steam exploded herbaceous agricultural waste (Brassica carinata) at different particule sizes," Process Biochemistry 38(2), 187-192. DOI: 10.1016/S0032-9592(02)00070-5

Berber-Mendoza, M. S., Martínez-Costa, J. I., Leyva-Ramos, R., Garcia, H. J. A., and Castillo, N. A. M. (2018). "Competitive adsorption of heavy metals from aqueous 
solution onto oxidized activated carbon fiber," Water, Air, \& Soil Pollution 229(8), 257-272. DOI: 10.1007/s11270-018-3906-y

Cao, J.-P., Huang, X., Zhao, X.-Y., Wang, B.-S., Meesuk, S., Sato, K., Wei, X.-Y., and Takarada, T. (2014). "Low-temperature catalytic gasification of sewage sludgederived volatiles to produce clean $\mathrm{H}_{2}$-rich syngas over a nickel loaded on lignite char," International Journal of Hydrogen Energy 39(17), 9193-9199. DOI: 10.1016/j.ijhydene.2014.03.222

Darmawan, S., Wistara, N. J., Pari, G., Maddu, A., and Syafii, W. (2016).

"Characterization of lignocellulosic biomass as raw material for the production of porous carbon-based materials," BioResources 11(2), 3561-3574. DOI: 10.15376/biores.11.2.3561-3574

Foroutan, R., Mohammadi, R., Farjadfard, S., Esmaeili, H., Saberi, M., Sahebi, S., Dobaradaran, S., and Ramavandi, B. (2019). "Characteristics and performance of Cd, $\mathrm{Ni}$, and $\mathrm{Pb}$ bio-adsorption using Callinectes sapidus biomass: Real wastewater treatment," Environmental Science and Pollution Research 26, 6336-6347. DOI: 10.1007/s11356-018-04108-8

Gong, Y. N., Jiao, L., Qian, Y.-Y., Pan, C.-Y., Zheng, L.-R., Cai, X.-C., Liu, B., Yu, S.H., and Jiang, H.-J. (2020). "Regulating the coordination environment of MOFtemplated single-atom nickel electrocatalysts for boosting $\mathrm{CO}_{2}$ reduction," Angewandte Chemie International Edition 59(7), 2705-2709. DOI: 10.1002/anie.201914977

He, Y.-C., Yang, J., Kan, W.-Q., and Ma, J.-F. (2013). “An ideal metal-organic rhombic dodecahedron for highly efficient adsorption of dyes in an aqueous solution," Crystengcomm 15(5), 848-851. DOI: 10.1039/c2ce26836a

Ho, Y. S., and McKay, G. (1999). "Pseudo-second order model for sorption processes," Process Biochemistry 34(5), 451-465. DOI: 10.1016/S0032-9592(98)00112-5

Hubbe, M. A., Azizian, S., and Douven, S. (2019). "Implications of apparent pseudosecond-order adsorption kinetics onto cellulosic materials. A review," BioResources 14(3), 7582-7626. DOI: 10.15376/biores.14.3.7582-7626

Hubbe, M. A. (2021). "Insisting upon meaningful results from adsorption experiments," Separation and Purification Reviews, Early access. DOI: 10.1080/15422119.2021.1888299

Khulbe, K. C., and Matsuura, T. (2018). "Removal of heavy metals and pollutants by membrane adsorption techniques," Applied Water Science 8(1), 19-49. DOI: 10.1007/s13201-018-0661-6

Kim, T.-S., Song, H. J., Dar, M. A., Lee, H.-J., and Kim, D.-W. (2018). "Fast adsorption kinetics of highly dispersed ultrafine nickel/carbon nanoparticles for organic dye removal," Applied Surface Science 439, 364-370. DOI: 10.1016/j.apsus c.2018.01.061

Li, Y., Zhong, J., Yang, X.-Z., Lan, G.-J., Tang, H.-D., and Liu, H.-Z. (2011). "Simple synthesis of semi-graphitized ordered mesoporous carbons with tunable pore sizes," New Carbon Materials 26(2), 123-129. DOI: 10.1016/S1872-5805(11)60071-1

Li, Q., Guo, J., Zhao, J., Wang, C., and Yan, F. (2019). “Porous nitrogen-doped carbon nanofibers assembled with nickel nanoparticles for lithium-sulfur batteries," Nanoscale 11(2), 647-655. DOI: 10.1039/c8nr07220e

Liu, Y., Lin, B., Li, D., Zhang, X., Sun, Y., and Yang, H. (2015). "Hierarchically porous graphitic carbon monoliths containing nickel nanoparticles as magnetically separable 
adsorbents for dyes," Journal of Applied Polymer Science 132(3), 41322-41329. DOI: 10.1002/app.41322

Liu, Y., Zhang, Z., and Wang, T. (2018). "Enhanced hydrogen storage performance of three-dimensional hierarchical porous graphene with nickel nanoparticles," International Journal of Hydrogen Energy 43(24), 11120-11131. DOI: 10.1016/j.ijhydene.2018.04.202

Panda, G. C., Das, S. K., Bandopadhyay, T. S., and Guha, A. K. (2007). "Adsorption of nickel on husk of Lathyrus sativus: Behavior and binding mechanism," Colloids and Surfaces B: Biointerfaces 57(2), 135-142. DOI: 10.1016/j.colsurfb.2007.01.022

Qian, K., Kumar, A., Zhang, H., Bellmer, D., and Huhnke, R. (2015). "Recent advances in utilization of biochar," Renewable and Sustainable Energy Reviews 42(1), 10551064. DOI: 10.1016/j.rser.2014.10.074

Reddy, D. A., Park, H., Ma, R., Kumar, D. P., Lim, M., and Kim, T. K. (2017). "Heterostructured $\mathrm{WS}_{2}-\mathrm{MoS}_{2}$ ultrathin nanosheets integrated on $\mathrm{CdS}$ nanorods to promote charge separation and migration and improve solar-driven photocatalytic hydrogen evolution," ChemSusChem 10(7), 1563-1570. DOI: 10.1002/cssc.201601799

Reddy, K. O., Maheswari, C. U., Dhlamini, M. S., Mothudi, B. M., Kommula, V. P., Zhang, J., Zhang, J., and Rajulu, A. V. (2018). "Extraction and characterization of cellulose single fibers from native African napier grass," Carbohydrate Polymers 188, 85-91. DOI: 10.1016/j.carbpol.2018.01.110

Ruan, X., Chen, Y., Chen, H., Qian, G., and Frost, R. L. (2016). "Sorption behavior of methyl orange from aqueous solution on organic matter and reduced graphene oxides modified Ni-Cr layered double hydroxides," Chemical Engineering Journal 297, 295 303. DOI: $10.1016 /$ j.cej.2016.01.041

Selvavathi, V., Chidambaram, V., Meenakshisundaram, A., Sairam, B., and Sivasankar, B. (2008). "Adsorptive desulfurization of diesel on activated carbon and nickel supported systems," Catalysis Today 141(1-2), 99-102. DOI: 10.1016/j.cattod.2008.05.009

Shi, W., Gao, H., Yu, J., Jia, M., Dai, T., Zhao, Y., Xu, J., and Li, G. (2016). “One-step synthesis of N-doped activated carbon with controllable Ni nanorods for ethanol oxidation," Electrochimica Acta 220, 486-492. DOI: 10.1016/j.electacta.2016.10.051

Song, Y., Ozdemir, E., Ramesh, S., Adishev, A., and Yavuz, C. T. (2020). "Dry reforming of methane by stable $\mathrm{Ni}-\mathrm{Mo}$ nanocatalysts on single-crystalline $\mathrm{MgO}$," Science 367(6479), 777-781. DOI: 10.1126/science.aav2412

Sulaiman, R. N. R., and Othman, N. (2017). "Synergistic green extraction of nickel ions from electroplating waste via mixtures of chelating and organophosphorus carrier," Journal of Hazardous Materials 340, 77-84. DOI: 10.1016/j.jh azmat.2017.06.060

Su, Q., Yang, S., He, Y., Qin, Z., and Cui, X. (2020). "Prepared self-growing supported nickel catalyst by recovering $\mathrm{Ni}$ (II) from metal wastewater using geopolymer microspheres," Journal of Hazardous Materials 389, 121919-121934. DOI: 10.1016/j.jhazmat.2019.121919

Wen, X.-J., Niu, C.-G., Zhang, L., and Zeng, G.-M. (2017). "Fabrication of $\mathrm{SnO}_{2}$ nanoparticles/BiOI n-p heterostructure for wider spectrum visible-light photocatalytic degradation of antibiotic oxytetracycline hydrochloride," ACS Sustainable Chemistry \& Engineering 5(6), 5134-5147. DOI: 10.1021/acssuschemeng.7b00501 
Woolf, D., Amonette, J. E., Street-Perrott, F. A., Lehmann, J., and Joseph, S. (2010). "Sustainable biochar to mitigate global climate change," Nature 1(1), 1-9. DOI: 10.1038/ncomms1053

Yin, W.-Y., Bian, T.-T., Geng, J., Hu, Y.-H., Yan, S.-Q., Tang, X.-Y., Cheng, H.-J., Ma, Y.-S., and Yuan, R.-X. (2018). "Synthesis, structure and adsorption studies of a nickel coordination polymer with selective removal on methyl orange," Inorganica Chimica Acta 476, 1-6. DOI: 10.1016/j.ica.2018.01.025

Zhou, G., Paek, E., Hwang, G. S., and Manthiram, A. (2015). "Long-life Li/polysulphide batteries with high sulphur loading enabled by lightweight three-dimensional nitrogen/sulphur-codoped graphene sponge," Nature Communications 6, 7760-7771. DOI: $10.1038 /$ ncomms 8760

Zheng, J. H., and Zhang, L. (2018). "Incorporation of CoO nanoparticles in 3D marigold flower-like hierarchical architecture $\mathrm{MnCo}_{2} \mathrm{O}_{4}$ for highly boosting solar light photooxidation and reduction ability," Applied Catalysis B: Environmental 237, 1-8. DOI: 10.1016/j.apcatb.2018.05.060

Zhong, Y., Xia, X., Deng, S., Zhan, J., Fang, R., Xia, Y., Wang, X., Zhang, Q., and Tu, J. (2018). "Popcorn inspired porous macrocellular carbon: Rapid puffing fabrication from rice and its applications in lithium-sulfur batteries," Advanced Energy Materials 8(1), 1701110. DOI: 10.1002/aenm.201701110

Zong, X., Yan, H., Wu, G., Ma, G., Wen, F., Wang, L., and Li, C. (2008). "Enhancement of photocatalytic $\mathrm{H}_{2}$ evolution on $\mathrm{CdS}$ by loading $\mathrm{MoS}_{2}$ as cocatalyst under visible light irradiation," Journal of the American Chemical Society 130(23), 7176-7177. DOI: $10.1021 / \mathrm{ja} 8007825$

Zou, W., Shao, Y., Pu, Y., Luo, Y., Sun, J., Ma, K., Tang, C., Gao, F., and Dong, L. (2017). "Enhanced visible light photocatalytic hydrogen evolution via cubic $\mathrm{CeO}_{2}$ hybridized g- $\mathrm{C}_{3} \mathrm{~N}_{4}$ composite," Applied Catalysis B: Environmental 218, 51-59. DOI: 10.1016/j.apcatb.2017.03.085

Article submitted: March 25, 2021; Peer-review completed: May 16, 2021; Revised version received: May 20, 2021; Accepted: June 13, 2021; Published: June 15, 2021. DOI: $10.15376 /$ biores.16.3.5481-5493 